\title{
Los valores de la ciencia y el papel de la ética en la ciencia
}

Hugh LaCey

Swarthmore College

Traducción: Luis Alvarenga

Departamento de Filosofía

UCA, San Salvador

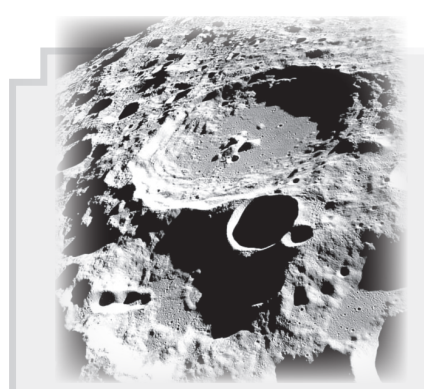

RESUMEN: El autor sostiene que es muy importante vincular las cuestiones acerca del papel de la ética en la ciencia con las cuestiones de los valores incorporados en las prácticas científicas.

ABSTRACT: The author maintains that it is very important to link the role of ethics in science with the values incorporated in scientific practices.

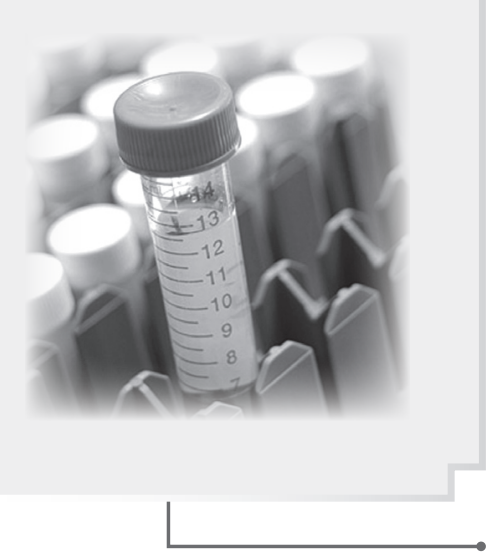




\section{El contexto}

Dor un lado, la ciencia moderna ha producido un enorme acervo de conocimiento confiable acerca de los fenómenos del mundo; y una buena parte de ellos ha sido usada para dar forma a incontables aplicaciones (en la tecnología, en la medicina y en otras áreas) que contribuyeron mucho para transformar fundamentalmente el mundo en que vivimos. Por otro lado, la actual crisis ambiental, con sus dimensiones humana y social, está entre las consecuencias de dichas aplicaciones (hechas bajo condiciones socioeconómicas propias de la modernidad) $-\mathrm{y}$ la ciencia no produjo el conocimiento que sería necesario para lidiar adecuadamente con dicha crisis.

Ahora, es evidente que la reflexión sobre la ciencia, en cuanto fenómeno social, debe abordar el hecho de que las aplicaciones del conocimiento científico tienen efectos colaterales no pretendidos y frecuentemente no anticipados, cuyas consecuencias pueden ser profundas. Esto suscita una pregunta importante: ¿cuáles deben ser las prioridades de la investigación científica?

Alguien puede proponer el punto de vista ético según el cual sería irresponsable emprender el tipo de investigación (por ejemplo, en biología molecular) capaz de dar pie a aplicaciones tecnológicas, a menos que - al mismo tiempo- también se emprendan investigaciones sistemáticas y rigurosas acerca de las consecuencias (riesgos) ecológicas y sociales de la implementación de dichas aplicaciones a largo plazo y acerca de las condiciones socioeconómicas de dicha implementación. Tal propuesta representaría un punto de vista ético sobre cómo debe conducirse la investigación científica y cuáles son sus prioridades, un punto de vista, por tanto, que no limita la reflexión ética sobre la ciencia — de acuerdo a la tendencia común- a los siguientes tres asuntos:

1. Cuestiones de ética de la investigación que involucran experimentos que utilizan sujetos humanos y animales y (más generalmente) cuestiones de derechos humanos que pudieran surgir a partir de las prácticas experimentales.

2. Cuestiones acerca de los beneficios y riesgos de las aplicaciones del conocimiento científico, a corto plazo y sin consideración de su contexto socioeconómico.

3. Elaboración del 'ethos científi$\mathrm{CO}^{\prime}$, esto es, identificación de las virtudes morales - honestidad, etc. - que supuestamente necesitan cultivarse para asegurar la integridad de la ciencia.

En lugar de esto, una propuesta como la que acabamos de presentar representa un punto de vista que rechaza la disociación entre dichos asuntos y las cuestiones sobre cómo los valores éticos y sociales tienen 
(y deben tener) influencia en el proceso total de investigación.

La propuesta más conocida de este tipo (que refleje, a partir de juicios éticos, cómo debe emprenderse la investigación hoy en día) recomienda que la investigación científica respete el principio de precaución (PP).

\section{El principio de precaución (PP)}

- s obligatorio practicar la precaución al respecto de las

- nuevas aplicaciones tecnocientíficas, en vista de sus riesgos potenciales y permitir —antes de implementar sus aplicaciones - un plazo razonable para realizar y avalar estudios ecológicos, sociales y otros que se muestren pertinentes.

De esta forma, el PP recomienda:

- Cautela de cara a la aplicación tecnológica de resultados científicos bien confirmados.

- Tomar conciencia de la importancia de emprender la investigación en áreas que no pueden investigarse adecuadamente utilizando sólo las metodologías de investigación que producen el conocimiento que da forma a las innovaciones tecnocientíficas.

El PP encuentra mucha oposición en las investigaciones científicas predominantes, precisamente por que admite un papel para la ética en la ciencia que se extiende más allá de los tres puntos enunciados anteriormente. Se dice frecuentemente que la adhesión al PP pone límites a la autonomía de la investigación científica, porque subordina los objetivos (prioridades) científicos a los imperativos éticos (y, así, debilita la autonomía conquistada tras la larga lucha que comenzó en el siglo XVII con el conflicto entre Galileo y la Iglesia).

Esta objeción presupone -correctamente- que las prácticas de la investigación científica incorporan ciertos valores. De acuerdo con una larga tradición científica, uno de esos valores es la autonomía.

AUTONOMía: Las prácticas científicas son autónomas: Los problemas de metodología científica y los criterios para avalar el conocimiento científico se encuentran fuera de la esfera de cualquier perspectiva ética (religiosa, política, social y 
económica) y no dependen de preferencias personales; las prioridades de la investigación, para el emprendimiento científico tomado como un todo, no deben moldearse por ninguna perspectiva valorativa en particular; y las instituciones científicas deben constituirse de forma que resistan las interferencias externas (no científicas).

Otro valor de las prácticas científicas es la objetividad (o imparcialidad).

OBJETIVIDAD: El conocimiento científico es objetivo: Una hipótesis se acepta como conocimiento científico —o una teoría se acepta como bien confirmada - en el momento en que se juzga que se encuentra bien apoyada por la evidencia empírica disponible, a la luz de criterios estrictamente cognitivos (por ejemplo, la adecuación empírica y el poder explicativo y predictivo), que no reflejen valores sociales y éticos particulares, y tan sólo después de haber sido puesta a prueba en el transcurso de un programa apropiado y riguroso de investigación empírica (experimental).

Otro valor de las prácticas científicas es, por otra parte, la neutralidad.

NEUTRALIDAD: El conocimiento científico y las teorías científicas son neutras: Los resultados científicos, considerados como un todo, no favorecen a algunas perspectivas éticas en desmedro de otras, ya sea a través de sus implicaciones lógica, o a través de las consecuencias concomitantes de sus aplicaciones; en el contexto de la aplicación (tecnológica), la totalidad de las teorías bien establecidas, en principio, puede servir equitativamente a los intereses promovidos por un amplio abanico de perspectivas éticas - esto implica que los resultados científicos pueden usarse al servicio de fines 'buenos' o 'malos'.

La neutralidad robustece la base de la idea de que los resultados científicos representan un patrimonio de la humanidad; y los tres valores en su conjunto constituyen la base racional del 'ethos científico'.

Pienso que es correcto avalar el PP por cuanto contribuye a una mayor manifestación de la autonomía, de la objetividad y de la neutralidad en las prácticas científicas. Empero, dicho aval debe ser comparativo y debe considerar, asimismo, cómo los demás abordajes (que se oponen a las propuestas del $\mathrm{PP}=$ podrían influir en la manifestación de los tres valores de las prácticas científicas $-\mathrm{O}$, talvez, otros valores que se piensa deben ser incorporados 
a las prácticas científicas (porque puede ser polémico discutir cuáles son los valores incorporados en las prácticas científicas).

El PP recomienda implementar con atraso las aplicaciones tecnocientíficas —durante el tiempo necesario para conducir la investigación sobre (entre otras cosas) los riesgos ecológicos y sociales de largo plazo de las implementaciones; $y$, asimismo, recomienda que se emprenda una investigación sobre asuntos que, hoy en día, son muy poco investigados. La recomendación está basada en parte en juicios éticos concernientes (entre otras cosas) a los derechos humanos, a la responsabilidad ambiental, el desarrollo sustentable, a la equidad intergeneracional y a la democracia participativa. En contraste, la mayor parte de la investigación tecnocientífica se comprende actualmente de aceurdo con un principio, al cual denomino el principio del presupuesto de la legitimidad de las innovaciones tecnocientíficas (PLT).

\title{
3. Principio del presupuesto de la legitimidad de las innovaciones tecnocientíficas (PLT)
}

\begin{abstract}
$P$ rima facie, la implementación de una innovación tecnocientífica es legítima, si esta fuese una aplicación de resultados científicos correctamente aceptados de acuerdo con la objetividad; o, normalmente, a menos que existe evidencia científica fuerte de que hay ciertos riesgos, es legítimo implementar — sin retraso- aplicaciones eficaces del conocimiento científico objetivamente comprobado.
\end{abstract}

El PLT, así como el PP, es un principio ético (tanto la legitimidad como la responsabilidad son conceptos éticos). El PLT es un presupuesto sustentado en las discusiones típicas de aplicaciones científicas, aunque frecuentemente sin conciencia, una vez que - debido a su ligazón con los valores del progreso tecnológico (ver Lacey, 2006b) - no es común ver que las instituciones actuales se hagan eco del PLT.
En oposición al PP, el PLT pone la carga de la prueba acerca de los riesgos en aquellos que piensan que, antes de la implementación social de una innovación, los riesgos deben investigarse amplia y rigurosamente. Generalmente, reflexionando sobre la falta de respuesta, el PLT se asocia al casi imperativo ético: priorizar las "soluciones" tecnocientíficas para los grandes problemas mundiales, como, por ejemplo, la desnutrición en los 
países pobres; e implica que es una deficiencia ética no sólo el que se ponga en duda el potencial o la legitimidad de la investigación y del desarrolla que puedan conducir a tales "soluciones", sino también el que se concentre la investigación en las relaciones socioeconómicas involucradas en la implementación de las "soluciones".

Hoy en día, como ya mencioné, la mayor parte de la investigación tecnocientífica se emprende a la luz del PLT. Eso forma parte del contexto del cambio rápido en las relaciones de producción del conocimiento científico, de cambio de una práctica predominantemente pública (en lo que respecta al financiamiento y al acceso a los resultados de la investigación) hacia una práctica que está bajo el control (en un grado significativo) de intereses privados y comerciales.

Pienso que deberíamos preguntar: ¿Qué sirve mejor para fortalecer los valores tradicionales de la ciencia - autonomía, objetividad y neutralidad-: La adopción del Principio de precaución o del principio de legitimidad técnica? Sugiero que, actualmente, esta es la cuestión ética más importante acerca de la ciencia.

\section{Bibliografía}

- Lacey, H. A controversia sobre os transgênicos: questões científicas e éticas. São Paulo: Idéias e Letras, $2006 a$.

- O Princípio de Precaução e a autonomia da ciência. Scientia Studia, 4, 3, p 373-92, 2006b.
Existe uma distinção relevante entre valores cognitivos e sociais? Scientiae Studia 1, 2, p. 121-49, 2003.

Mariconda, P. \& Lacey, H. A águia e os estorninhos: Galileu sobre a autonomia da ciência. Tempo Social, 13, p. 49-65, 2001. 